\title{
Hand-Arm Vibration, Noise, Temperature and Static Load
}

\section{- An Experimental Study of Peripheral Circulation while Operating Chain-saws-}

\author{
TAKASHI MIYAKITA, HAJIME MIURA and MAKOTO FUTATSUKA* \\ Departments of Hygiene and ${ }^{*}$ Public Health, Kumamoto University Medical School, \\ Kumamoto, 860 Japan
}

Received for publication May 22, 1989

\begin{abstract}
Summary: From the viewpoint of elucidating the etiological mechanism of vibration-induced white finger (VWF), a model experiment was designed using a chain-saw under laboratory conditions. Finger skin temperature and finger blood flow were measured simultaneously as indicators of peripheral circulatory movement, using a thermister and an apparatus for measuring tissue blood flow based on the thermal diffusion method. In the first project (Experiment A), five healthy subjects operated a chain-saw at a high working speed without actually cutting anything. In the second project (Experiment B), seven healthy subjects were exposed to three different kinds of experiments with combinations of hand-arm vibration, noise and tool weight at about $15^{\circ} \mathrm{C}$ room temperature. In the third project (Experiment C), the effects of tool weight and grip force were examined. In the fourth project (Experiment D), patients suffering from vibration disease were exposed to hand-arm vibration and the noise of a chain-saw for 2 minutes. In experiment $A$, the mean value of the normalized finger skin temperature decreased gradually with cyclic changes corresponding to each exposure and break period. Changes in finger blood flow had almost the same pattern as the changes of skin temperature, but the recovery of blood flow during a $30 \mathrm{sec}$ break period was notable and a slight elevation of the base line was observed. In experiment $B$, the mean value for the normalized finger skin temperature decreased much more when the subjects operated a chain-saw at a high working speed than when they operated the chain-saw with the noise isolated by double hearing protection. On the other hand, the results obtained in experiment $\mathrm{C}$ indicated that the effect of tool weight should be considered as an important factor for investigating the acute changes in peripheral circulation. In experiment $D$, some patients showed an unusual pattern in the change of blood flow during a post exposure period which was not seen in healthy subjects.
\end{abstract}

Key words: skin temperature - skin blood flow - chain-saw operationsympathetic nervous system - vasoconstriction

\section{Introduction}

Workers using vibrating tools, such as chain-saws, for prolonged periods develop various symptoms relating to the peripheral circulation, peripheral nerves, muscles, bones and joints (Taylor and
Brammer, 1982). The vascular symptom, vibration-induced white finger (VWF), has been extensively investigated (Azuma and Ohhashi, 1982; Cohen and Coffman, 1984; Gemne, 1982; Pyykkö et al. 1982; Yodaiken et al. 1985), but its etiological mechanism is still obscure. During studies 
of the physiological effects of chain-saw operation, it is necessary to take into account not only vibration factors but also other contributing factors such as noise, working conditions (handle grasping power and work posture) and ambient temperature. In a previous paper (Miyakita et al. 1987), it was shown that a combination of noise and vibration produced more pronounced changes in the temporary shift of finger skin temperature than exposure to either stress alone. This indicated that the sympathetic nervous system has a role in the changes in peripheral circulation. Skin temperature is considered to reflect the blood flow in a relatively deep part of the skin vascular bed; but it also depends on the environmental temperature and on the modes of heat balance. In this study skin temperature and skin blood flow were measured simultaneously. The purpose of the study was to observe the peripheral circulation while operating chain-saws with an emphasis on the contributions of tool weight and grip force to acute changes in blood flow. In addition, preliminary results regarding patients suffering from vibration diseases will be presented.

\section{Subjects and Methods}

\section{Subjects}

In experiments $\mathrm{A}, \mathrm{B}$ and $\mathrm{C}$, the subjects were 12 healthy adult men, students and researchers, who were all volunteers and who had not previously been exposed to the environmental factors involved. Their ages ranged from 20 to 50 years. In experiment $\mathrm{D}, 33$ patients, age 51 to 79 , undergoing a medical treatment for vibration diseases served as subjects.

\section{Observation Methods}

Finger skin temperature was measured every 30 seconds (every 15 seconds in the rest period between exposure periods) by a thermister (Takara D-925). The thermosensor was attached to the dorsal skin surface of the distal phalangeal joint of the third finger. Finger blood flow was measured by an apparatus for measuring tissue blood flow based on thermal diffusion methods (BMS BTG-III) (Nakamura, H. 1987). An electrode with a Peltier stack (BMS TGD-8G) was attached to the dorsal skin surface of the middle phalangeal joint of the third finger.

\section{Experimental design (Table 1)}

In Experiment $A$ five healthy subjects operated a chain saw (Shingu SP 500D) at a high working speed (sound level 105 dBA) without actually cutting at a room temperature between $20^{\circ} \mathrm{C}$ and $24^{\circ} \mathrm{C}$. The vibration level of the loaded left handle was $153.5 \mathrm{~dB}\left(0 \mathrm{~dB}\right.$ ref $10^{-6} \mathrm{~m} / \mathrm{s}^{2}, \mathrm{X}$-axis), $149 \mathrm{~dB}$ ( $\mathrm{Y}$-axis) and $151.5 \mathrm{~dB}$ ( $\mathrm{Z}$-axis) during the chain-saw operation at a sound

TABLE 1

Experimental design

\begin{tabular}{llccccc}
\hline & & Vibration & Noise & Weight & Grip force & Temperature \\
\hline Experiment & A & + & $+(105 \mathrm{dBA})$ & + & + & $22^{\circ} \mathrm{C}$ \\
Experiment & $\mathrm{B}-1$ & + & $+(105 \mathrm{dBA})$ & + & + & $15^{\circ} \mathrm{C}$ \\
& $\mathrm{B}-2$ & + & $+(<65 \mathrm{dBA})$ & + & + & $15^{\circ} \mathrm{C}$ \\
& $\mathrm{B}-3$ & + & $+(105 \mathrm{dBA})$ & - & - & $15^{\circ} \mathrm{C}$ \\
Experiment & $\mathrm{C}-1$ & - & - & - & $0-5 \mathrm{~kg}$ & $22^{\circ} \mathrm{C}$ \\
& $\mathrm{C}-2$ & - & - & $0-10 \mathrm{~kg}$ & + & $22^{\circ} \mathrm{C}$ \\
\hline
\end{tabular}




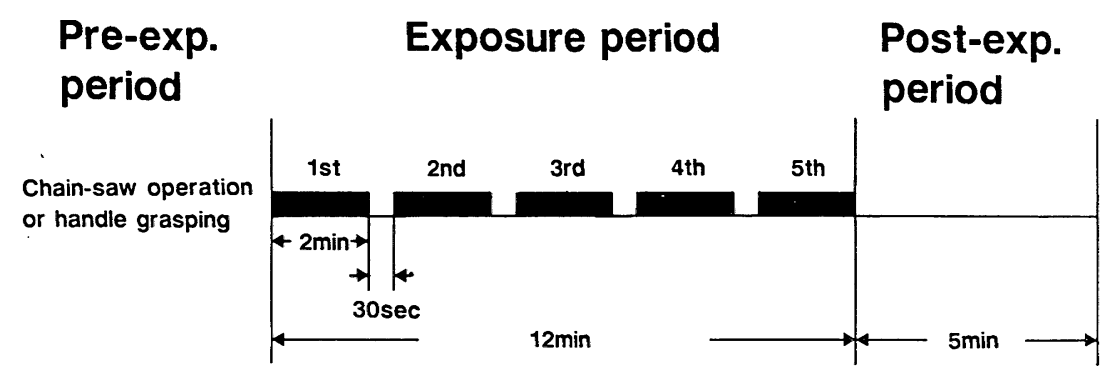

Fig. 1. Schematic representation of the time profile in experiments $\mathrm{A}, \mathrm{B}$ and $\mathrm{C}$.

level of $105 \mathrm{dBA}$. The weight of the chainsaw was $7.9 \mathrm{~kg}$.

In Experiment $B$ seven healthy subjects were exposed to three different kinds of experiments involing combinations of hand-arm vibration, noise and tool weight at about $15^{\circ} \mathrm{C}$ room temperature.

Experiment $B$-1: the subjects operated the chain saw at a high working speed (sound level, $105 \mathrm{dBA}$ ) without actually cutting.

Experiment $B-2$ : the subjects operated the chain-saw with the noise isolated by double hearing protection. The attenuation in $\mathrm{dB}$ at $4 \mathrm{kHz}$ was $41.9 \pm 2.1$ for the ear plug (DESI DAMP) and $42.0 \pm 3.2$ for the ear muff (Bilson No 2318), tested in accordance with ANSI S3. 19-1974.

Experiment $B$-3: the subjects operated a chain saw which was suspended from the ceiling by a chain. They grasped the handle of the chain-saw without exerting any grip force (touching only).

Experiment $C$ was aimed to investigate the effects of varied grip forces (in 5 steps) and the effects of the weight, itself, on peripheral circulation.

Experiment $C$-1: the chain saw was suspended from the ceiling by a chain and the subjects grasped its handle with the left hand at grip forces of 0 to $5 \mathrm{~kg}$. Grip force was monitored by a load meter (Toyoda AA 1650).

Experiment $C$-2: the subjects carried a bucket in their left hand. The weight of the bucket was varied from 1 to $10 \mathrm{~kg}$.

The time profile of experiments A, B and $\mathrm{C}$ consisted of a 30 minute pre-exposure period followed by five exposure periods each lasting two minutes and immediately followed by a 30 second break, and finally a post exposure (recovery) period of 5 minutes (Fig. 1).

In Experiment $D \quad 33$ patients suffering from vibration disease operated a chainsaw (Shingu SP 500D, Echo 651T, or Husqvarna $480 \mathrm{CDS}$ ) at a high working speed for two minutes without actually cutting.

\section{Results}

\section{Experiment $A$}

Figs. 2 and 3 show the changes in normalized finger blood flow during chain-saw operations for subjects $\mathrm{F}$ and $\mathrm{U}$ on five occasions, to show the intra-individual variation. The trends of the individual curves were relatively similar in both of the subjects. The average finger blood flow of the five subjects, together with the average finger skin temperature in experiment A, are shown in Fig. 4. The room temperature was about $22^{\circ} \mathrm{C}$. The mean values of the normalized finger skin temperature decreased gradually with cyclic changes corresponding to each exposure and break period. Changes in finger 


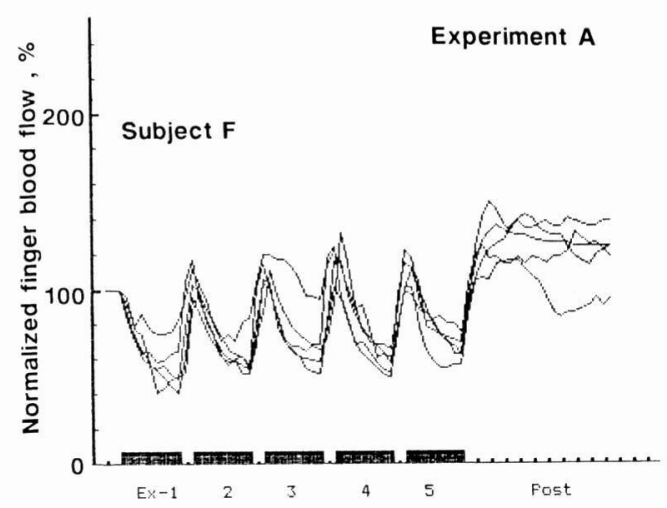

Fig. 2. Changes in normalized finger blood flow for subject $F$ on five occasions, to show the reproducibility.

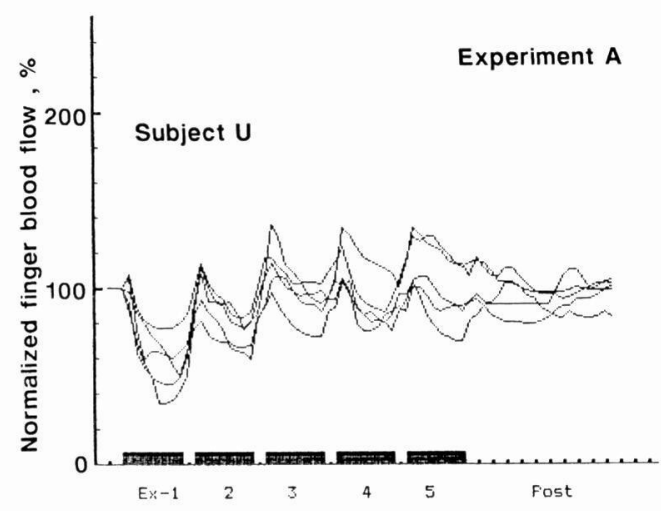

Fig. 3. Changes in normalized finger blood flow for subject $U$ on five occasions, to show the reproducibility.

blood flow had almost the same pattern as the changes of skin temperature, but the recovery of blood flow during each 30 sec break period was notable and a slight elevation of the base line was observed.

\section{Experiment $B$}

Fig. 5 shows the relation between the average finger blood flow and the average finger skin temperature of the seven subjects in experiment B-1. The room temperature was about $15^{\circ} \mathrm{C}$. In contrast with the result obtained in experiment $\mathrm{A}$, the rate of decrease in skin temperature was

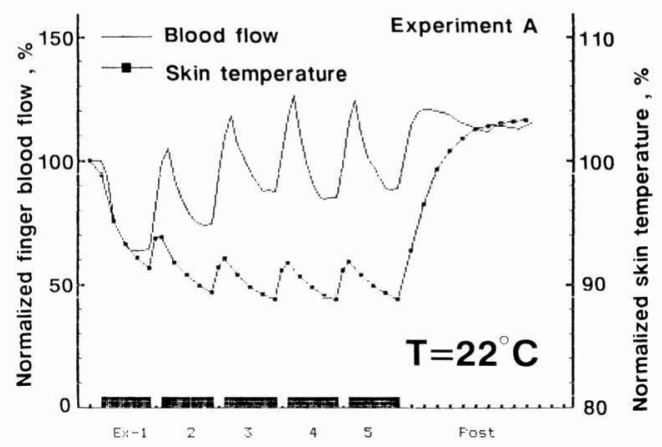

Fig. 4. Average finger blood flow of five subjects, together with the average finger skin temperature of these subjects during chain-saw operation (Experiment A).

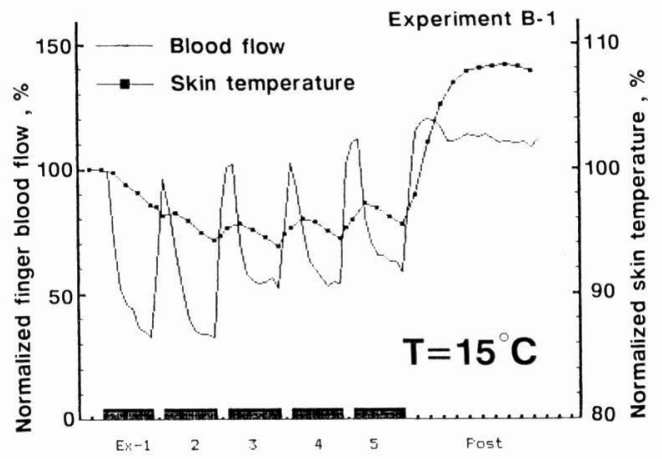

Fig. 5. Average finger blood flow of five subjects, together with the average finger skin temperature of these subjects during chain-saw operation (Experiment B-1).

small. As shown in Fig. 6, the mean normalized finger skin temperature decreased much more when the subjects operated the chain-saw at a high working speed (experiment B-1) than when they operated the chain-saw with the noise isolated by double hearing protection (experiment B-2). In experiment B-3 a decrease in finger skin temperature was not observed in the early stages, although a cyclic decrease in finger blood flow was recognized that corresponded to each exposure and break period (Fig. 6, 7). The differences in the changes of blood flow between ex- 


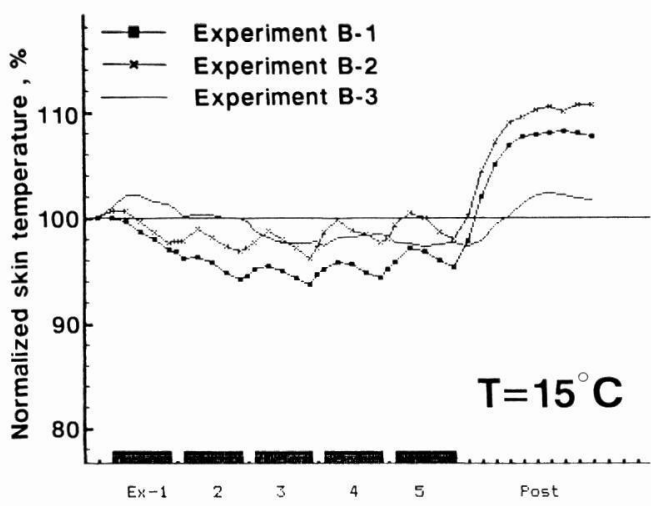

Fig. 6. Changes in average finger skin temperature of seven subjects in experiments $\mathrm{B}-1, \mathrm{~B}-2$ and $\mathrm{B}-3$.

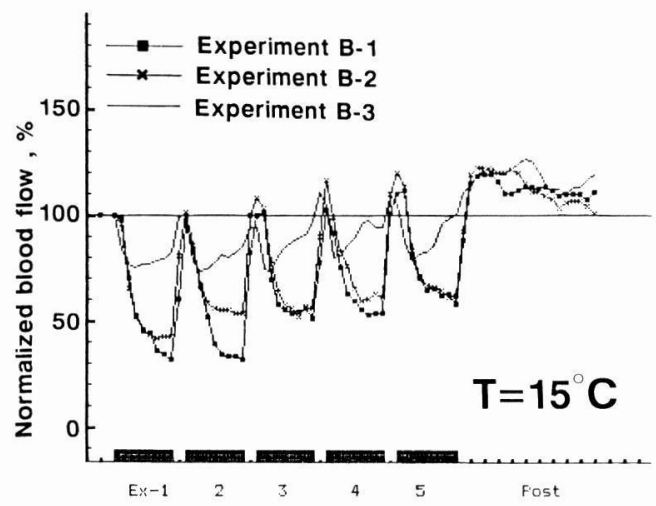

Fig. 7. Changes in average finger blood flow of seven subjects in experiments B-1, B-2 and B-3.

periments $\mathrm{B}-3$ and $\mathrm{B}-1$ and between experiments B-3 and B-2 were significant. On the other hand, between experiment B- 1 and experiment B- 2 the difference in the changes of blood flow was not significant except during the second round of exposure (Fig. 7).

\section{Experiment $C$}

Fig. 8 shows the effects of the grip force, which is considered to be an important factors. The blood flow increased

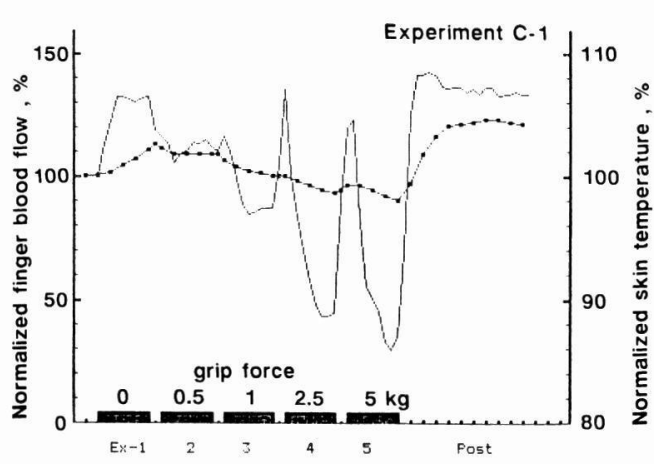

Fig. 8. Effects of varied grip forces on peripheral circulation. Subjects grasped the handle of a chain-saw at grip forces of 0 to $5 \mathrm{~kg}$.

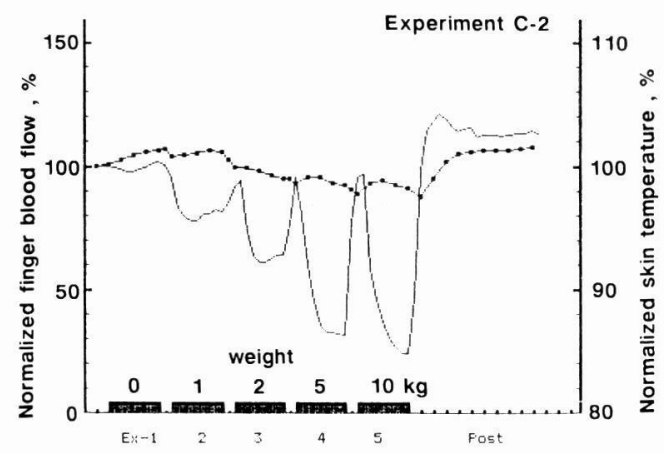

Fig. 9. Effects of handling heavy objects. Subjects carried a bucket in their left hand. The weight of the bucket varied from 1 to $10 \mathrm{~kg}$.

at grip forces of 0 (grip touch only) and $0.5 \mathrm{~kg}$, but it decreased continuously as the force was increased from 1 to $5 \mathrm{~kg}$. The skin temperature changed slower than the blood flow. Fig. 9 shows the effects of handling heavy objects. A clear tendency was observed showing a decrease of blood flow with increases in weight. The decreases in the skin temperature were relatively slow and small, and a time lag was observed between the changes in blood flow and skin temperature. 


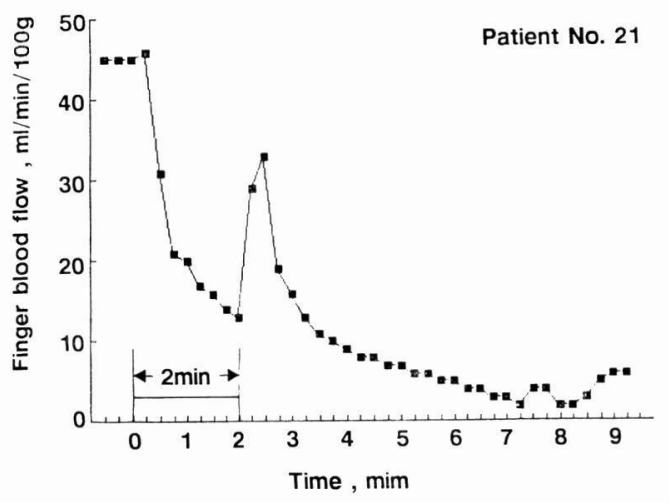

Fig. 10. Changes in finger blood flow during a chain-saw operation for two minutes and during a post exposure period.

\section{Experiment $D$}

As shown in Fig. 10, some patients had unusual changes of blood flow during the post exposure period. Finger blood flow decreased during the two minute exposure period, and after cessation of the exposure there was a further significant decrease, instead of a rapid recovery to the base line.

\section{Discussion}

Changes in finger blood flow during chain-saw operations depend on many contributing factors:

(1) the effects of handle grasping power, that is, the reduction in peripheral circulation induced by the mechanical compression of the skin vascular bed.

(2) the effects of sustained muscle exertion (i.e. lifting and holding a chainsaw for a given period of time) on blood distribution in muscles and in the skin surface.

(3) direct effects of local vibration transmitted from the handle of the chainsaw to the skin surface, muscles and blood vessels.

(4) indirect effects of noise and local vibration on peripheral circulation mediated by the sympathetic nervous system.

On the other hand, the changes in skin temperature must be evaluated with due consideration of the microclimate around the thermo-sensor. Thauer (1965) pointed out that skin temperature can change without any change in skin blood flow, and blood flow can change without affecting the skin temperature. That is, different values of blood flow may correspond to the same skin temperature, and vice versa. Furthermore the capillary bed of the skin has a number of distinct structural elements which regulate the capillary flow. Therefore, it is not easy to relate the changes in finger blood flow to skin temperature under different exposure conditions.

Before evaluating the results obtained in this study, the complex structure of the skin vascular bed must be addressed, especially the microcirculation. The blood vessels of the skin form a three dimensional vascular meshwork, which was nicely illustrated by Sparks (1978). They are distinguished by their extensive interarterioral arcades forming a horizontal plexus (cutaneous arterial plexus and subpapillary arterial plexus), by frequent arteriovenous communications, by a large venous system (upper and deep subpapillary venous plexus) and by the distribution of microcirculatin units (Short, 1979; Higgins and Eady, 1981). The components of the cutaneous microcirculation are the terminal arteries, metarterioles, precapillary sphincters, capillary loop and post capillary venules. The circulation of blood from arteries to veins can take various routes via thoroughfare channels, true capillaries, and arteriovenous or arteriolvenous shunts (anastomoses). The pressure gradient and the activity of the smooth-muscle cells in the walls or the precapillary sphincters determine which route the blood flow will take (Åstrand and Rodah1, 1977). Because of these fac- 
tors, it is difficult to relate microcirculatory phenomena reflected in changes of skin temperature and skin blood flow to microcirculatory controls induced by various contributing factors such as local vibration, noise and static load.

Under normal physiological conditions, the blood flow in the cutaneous vessels of the hands and feet is primarily controlled by sympathetic adrenergic vasoconstrictor fibers, in contrast to many other areas of the body which are supplied by both vasoconstrictor and vasodilator sympathetic fibers (Halperin and Coffman, 1979; Yodaiken et al. 1985). This cutaneous vasoconstriction is most pronounced in the acral part, primarily because of the presence of a great number of arteriovenous anastomoses which are tightly closed by the constrictor impulses (Ryan, 1955). In the skin of the fingers and feet, Grant and Bland (1931) counted 93-501 anastomoses per $\mathrm{mm}^{2}$. Radioactive isotope studies by Brakkee and Vendrik (1970) suggested that some $60 \%$ of the blood volume in the skin passes through such shunts. Coffman and Cohen (1971) estimated that $75 \%$ of the finger tip blood flow may be through arteriovenous anastomoses. Furthermore there are special arteriovenous anasotmoses called glomus bodies, consisting of tortuous channels, epitheloid walls, a large number of nerve endings and connective tissue sheaths (Sparks, 1978; Ryan, 1983). According to the description of Short (1979), the innervation of the glomus body is extensive; it may receive both adrenergic and cholinergic nerve fibers. The role of sympathetic cholinergic vasodilator fibers has been emphasized by Hurley and Mescon (1956). Even in laboratory conditions, operating a chain-saw involves several contributing factors which can affect the complex system of microcirculation in many ways.

In experiment B-3, since the chain-saw was suspended from the ceiling and the amount of coupling due to the hand grip was small, the effects of tool weight and grip force on peripheral circulation were considered to be negligible. Accordingly, the differences in blood flow changes between experiments B- 1 and B- 3 indicated that grip force is one of the contributing factors (Fig. 7).

In experiment $\mathrm{C}-1$, the subjects grasped the handle of the chain-saw, which had been suspended by a chain from the ceiling, with their left hand at a grip force of 0 to $5 \mathrm{~kg}$. As shown in Fig. 8 , there were decreases of both finger skin temperature and blood flow with increases in grip force (1, 2.5 and $5 \mathrm{~kg}$ ). The increase of blood flow at a grip force of 0 and 0.5 $\mathrm{kg}$ may be the result of insufficient pressure to close the minute vessels of the skin, because the connective tissue supporting the cutaneous vessels has considerable toughness and flexibility and encloses the channels in such a way as to protect the channels from easy closure due to extraneous forces (Ryan, 1983). In Experiment $\mathrm{C}-2$, the subjects carried a bucket weighing 1 to $10 \mathrm{~kg}$. Although the muscles involved in this static load and the blood distribution in the muscles and in the skin surface are slightly different from those in Experiment C-1, nearly the same tendency was obtained as in experiment $\mathrm{C}-1$; that is, a notable decrease of blood flow depending on the weight, was recognized. A time lag for changes of skin temperature may be explained by a lag period between changes in blood flow heating the skin and the time taken for the warmth to penetrate to the surface (Ryan, 1983). Besides, the skin temperature depends on the tissue thermal capacity of not only the skin but also of muscles and bones. These results support the hypothesis that the direct temporary effects of handle grasping play an important role in the changes in peripheral circulation observed during the operation of vibrating tools (Dupuis, 1987; Nakamura et al. 1987). 
The direct effects of local vibration transmitted from the handle of the chainsaw to the skin surface, muscles and blood vessels are still unclear. Although the acute decrease of blood flow observed in experiment B-3 results from both noise and local vibration (Fig. 7), it is unclear whether these two factors act synergistically or antagonistically. Ljung and Sivertsson $(1972,1975)$ reported that longitudial vibrations promptly reduced the contractile force of the vascular smooth muscle in isolated preparations of rat portal vein and rabbit thoracic aorta. In an experiment with isolated canine femoral arteries, Azuma et al. (1978) found that the responsiveness of experimental strips to noradrenaline decreased during, and increased after, application of vibratory stimulation. On the other hand, Folkow et al. (1972) and Hallback et al. (1974) demonstrated that vibration raised the peripheral vascular tone of rats by activating central vasoconstrictor mechanisms. Recently, Nakamura et al. (1987) observed a significant increase of finger blood flow and a significant fall of the skin temperature during local vibration exposure $(60$ $\mathrm{Hz}, 50 \mathrm{~m} / \mathrm{sec}^{2}$ and $480 \mathrm{~Hz}, 50 \mathrm{~m} / \mathrm{sec}^{2}$ ). On the basis of the hypothesis that vibration exerts a direct depressant action on the contractile process by causing an increased rate of detachment of actin-myosin crosslinkages (Ljung and Sivertsson, 1975), they suggested that vibration stimuli may have a vasodilating action in digital vessels. In the present model experiments using a chain-saw, it will be very difficult to separate the direct effects of local vibration transmitted from the handle of the chain-saw and the indirect effects of local vibration mediated by the sympathetic nervous system.

It is well established that the changes in skin blood flow due to the constricition and dilation of skin blood vessels are under the control of autonomic, humoral and local mechanisms (Roddie, 1983;
Renkin, 1984). Metarterioles and precapillary sphincters are particularly sensitive to nonnervous stimulation, for instance, by epinephrine, norepinephrine and substances arising locally from tissue metabolism; while sympathetic nerve impulses act primarily on arterioles and arteriovenous anastomoses (Ryan, 1955). Hales et al. (1978) showed that blood flow through cutaneous arteriovenous anastomoses (deeper vessels) is controlled by specific thermoregulatory reflexes, whereas cappillary flow (superficial vessels) is the target of local temperature effects. Nagasaka et al. (1987) referred to the control mechanism for partitioning of skin circulation between arteriovenous anastomoses and resistance vessels. Pyykkö et al. (1982) exposed workers with VWF and controls to noise, vibration and body cooling, and documented, using fingerpulse plethysmography, that strong vasospasms occurred significantly more frequently during vibration exposure in workers with VWF than in the controls. They emphasized the role of the central nervous system mediated by efferent sympathetic vasoconstrictor fibers, and an afferent reflex arc triggered by Pacinian corpuscles. Kondou et al. (1987) reported that local vibratory application yielded vasoconstriction in the remote digits, as well as in the neighbouring region, and suggested the contribution of the somatosympathetic reflex mechanism. In an earlier study using the chain-saw (Miyakita et al. 1987), a combination of noise and vibration produced more pronounced changes in finger skin temperature than exposure to either stress alone. This synergistic action of noise and vibration also supports the idea of participation of the sympathetic nervous system. The results obtained in Experiment A clearly showed the state of the peripheral circulation dur ing chain-saw operations (Fig. 4). The increased metabolism due to sustained muscle exertion (lifting and holding a 
chain-saw) may result in a slight elevation of the base line blood flow (Fig. 4). This did not occur in experiment B-1 which was carried out at $15^{\circ} \mathrm{C}$. Åstrand and Rodahl (1977) observed that during exercise the blood vessels of the skin, especially the arteriovenous anastomoses, dilated so that the produced heat was transported to the surface area of the body. The heavier the exercise and the higher the environmental temperature, the more pronounced was this secondary vasodilation in the skin.

As a general rule, the release of the external pressure due to handle grasping leads to a rapid increase of blood flow beyond the normal base line. This phenomenon has been known as reactive hyperemia (Ryan, 1955; Sparks, 1978). But, in experiment $\mathrm{D}$, some patients had a different pattern of blood flow during the post exposure period. That is, finger blood flow decreased during a two minute exposure period; and after cessation of the pressure, the flow was even further significanty decreased (Fig. 10). This specific decrease in blood flow can be explained by Azuma's observation concerning the direct effects of vibration. They reported that the responsiveness of arteries to noradrenaline was markedly enhanced after cessation of vibratory stimulation (Azuma and Ohhashi, 1982). The relationship between this phenomenon and the severity of the VWF is uncertain.

The thermal diffusion method, used in the present study, is based on a linear relationship between thermal conductivity of tissue and tissue blood flow. Nakamura (1987) showed that the voltage difference of thermocouples on the skin gradually increased in parallel with the finger ischemia induced by inflation of a pneumatic tourniquet from 0 to $300 \mathrm{mmHg}$. One of the problems encountered in the present experiments with this method is that the determination of the zero value in each of the subjects by occlusion of the bra- chial artery is not necessarily valid for quantitative comparisons of average values under different exposure conditions. The peripheral circulatory movement during chain-saw operations is very complicated compared with that resulting from the occlusion of the brachial artery induced by a pneumatic cuff. Therefore, further research is needed to clarify the implications of the results obtained in the present study.

\section{References}

Åstrand, P.O. and Rodahl, K. ed. (1977). Textbook of Work Physiology. New York: McGrow-Hill

Azuma, T., Оhнashi, T. and Sakaguchi, M. (1978). Vibration-induced hyperresponsiveness of arterial smooth muscle to noradrenaline with special reference to Raynaud's phenomenon in vibration disease. Cardiovasc. Res. 12, 758764.

Azuma, T. and Оннаshi, T. (1982). Pathophysiology of vibration-induced white fingr: etiological considerations and proposals for prevention. In Vibration Effects on the Hand and Arm in Industry, Brammer, A. J. and Taylor, W., eds. pp. 295-307. New York: John Wiley and Sons.

BrakkeE, A. J.M. and Vendrik, A. J. H. (1970). Arterio-venous shunts in peripheral vascular systems. Pflugers Arch. 314, 170.

Coffman, J.D. and Cohen. A. S. (1971). Total and capillary fingerttp blood flow in Raynaud's phenomenon. N. En'tl. J. Med! 285, 259-263.

Cohen, R. A. and Coffman, J. D. (1984). Digital vasospasm: the pathophysiology of Raynand's phenomenon Int. Angio. 3, 47-55.

Dupuis, H. (1982). Combined effects of handarm-vibration, air temperature, noise and static load on skin temperature. In Recent advances in researches on the combined effects of environmental factors, Okada, A. and Manninen, O., eds. pp. 295-307. Kanazawa, Japan: Kyoei.

Folkow, B., Hallbäck, M. and Weiss, L. (1972). Cardiovascular responses to acute mental stress in spontaneously hypertensive rats (SHR). Acta Phyiol. Scand. 84, 7A-8A. 
Gemne, G. (1982). Pathophysiology and multifactorial etiology of acquired vasospastic disease (Reynaud syndrom) in vibration-exposed workers. Scand. J. Work Environ. Health 8, 243-249.

Grant, R. T. and Bland, E.F. (1931). Observations on arteriovenous anastomoses in human skin and in the bird's foot with special reference to the reaction to cold. Heart 15, 385-407.

Hales, J. R. S., Fawcett, A. A., Bennett, J. W. and NeEdham, A.D. (1978). Thermal controls of blood flow through capillaries and arteriovenous anastomoses in skin of sheep. Pflügers Arch. 378, 55-63.

Hallbäck, M. and Folkow, B. (1974). Cardiovascular responses to acute mental stress in spontaneously hypertensive rats. Acta Physiol. Scand. 90, 684-698.

Halperin, J.L. and Coffman, J.D. (1979). Pathophysiology of Raynaud's disease. Arch. Intern Med. 139, 89-92.

Higgins, J.C. and EADY, R. A. J. (1981). Human dermal microvasculature: I. Its segmental differentiation. Light and electron microscopic study. Brit. J. Derm. 104, 117-129.

Hurley, H. J. and Mescon, H. (1956). Cholinergic innervation of the digital arteriovenous anastomoses of human skin. A historical loclization of cholinesterase. J. Appl. Physiol. 9, 82-84.

Kondou, T., Sakakibara, H. and Miyao, M. et al. (1987). Effect of exposure to hand-transmitted vibration on digital skin temperature change. Ind. Health, 25, 41-53.

Ljung, B. and Sivertsson, R. (1972). The inhibitory effect of vibrations on tension development in vascular smooth muscle. Acta Physiol. Scand. 85, 428-430.

Ljung, B. and Sivertsson, R. (1975). Vibrationinduced of vascular smooth muscle contraction. Blood Vessels, 12, 38-52.

Miyakita, T., Miura, H. and Futatsuka, M. (1987). An experimental study of the physiological effects of chain saw operation. Brit. J. Ind. Med. 44, 41-46.

Nagasaka, T., Nunomura, T. and Hirata, $K$. (1987). Partitional measurement of finger circulation between blood vessels located deeply and those located superficially. In Microcirculation an update, Vol. 2, ed. Tsuchiya et al. pp. 507-508. Amsterdam: Excerpta Medica.

Nakamura, H., Nohara, S., Nakamura, H. and
ОкаDA, А. (1987). Combined effects of local vibration and noise on peripheral circulatory function. In Recent Advances in Researches on the Combined Effects of Environmental Factors, Okada, A. and Mannimen, O. eds. pp. 762-781. Kanazawa, Japan: Kyoei.

Nakamura, H. (1987). Development of a system for monitoring the body surface circulation and its application. Part 1 Fundamental study. Jpn. J. Hyg. 41, 896-913.

PyykKö, I., Hyvärinen, J. and FärkKILÄ, M. (1982). Studies on the etiological mechanism of the vasospastic component of the vibration syndrome. In Vibration effects on the hand and arm in industry, Brammer, A. J. and Taylor, W. eds. pp. 13-24. New York: John Wiley and Sons.

RENKIN, E. M. (1984). Control of microcirculation and blood-tissue exchange. In Handbook of Physiology. Sec 2, Vol. 4, pp 627-687. Bethesda: American Physiological Society,

RodDiE, I.C. (1983). Circulation to skin and adipose tissue. In Handbook of Physiology. Sec 2, Vol. 3, pp 285-317. Bethesda: American Physiological Society.

Ryan, T. J. (1955). Circulation and vascular reactions. In Physiology and Biochemistry of the skin. ed. Rothman, S. pp 60-119. Chicago and London: The University of Chicago Press.

Ryan, T. J. (1983). Cutaneous circulation. In Biochemistry and Physiology of the Skin. ed. Goldsmith, L. A., pp 817-877. New York: Oxford University Press.

Short, J. M. (1979). Diseases of the blood vessels. In Clinical Dermatology. Vol. 2, eds. Demes, D. J., Dobson, R. L. and McGuire, J. pp. 1-9. Hagerstown, Md: Harper and Row.

Short, J. M. (1979). Diseases of the blood vessels. In Clinical Dermatology, Vol. 2. eds. Demes, D. J. et al. pp. 1-9. Hagerstown: Harper and Row.

TAYLOR, W. and Brammer, A. J. (1982). Vibration effects on the hand and in industry: an introduction and review. In Vibration effects on the hand and arm in industry, eds. Brammer, A. J. and Taylor, W. pp. 1-12. New York: John Wiley and Sons.

Thauer, R. (1965). Circulatory adjustments to climatic requirements. In Handbook of Physiology. Sec 2, Vol. 3, eds. Hamilton, W. F. and Dow, P. pp. 1921-1966. Bethesda: American physiological Society.

Yodaiken, R. E., Jones, E. and Kunicki, R. (1985). 
The Raynaud phenomenon of occupational origin. In Advances in Microcirculation, Vol.
12, Altura, B. M. and Davis, E.,eds. pp. 6-33 Basel: S. Karger. 